\title{
Effect of estradiol replacement in ovariectomized NMRI mice in response to acute and chronic stress
}

\author{
Negin Ghobadi ${ }^{1}$, Hedayat Sahraei ${ }^{2}$, Gholam Hossein Meftahi ${ }^{2} *$ Maryam Bananej $^{1}$, Sara Salehi ${ }^{1}$ \\ ${ }^{1}$ Department of Biology, School of Biological Sciences, Islamic Azad University, North Tehran Branch, Tehran, Iran. \\ ${ }^{2}$ Neuroscience Research Center, Baqiyatallah, University of Medical Sciences, Tehran, Iran.
}

\begin{tabular}{l} 
ARTICLE INFO \\
\hline Article history: \\
Received on: $31 / 08 / 2016$ \\
Revised on: $23 / 09 / 2016$ \\
Accepted on: $14 / 10 / 2016$ \\
Available online: $29 / 11 / 2016$ \\
\hline Key words: \\
Adrenal gland, Anorexia, \\
Cortisol, Food intake, Mice, \\
Ovarectomy.
\end{tabular}

\begin{abstract}
The effect of intraperitoneal (IP) and intraventricular (ICV) injection of 17- $\beta$-estradiol on hormonal and metabolic changes induced by acute and chronic stress in ovariectomized female NMRI mice was evaluated. NMRI female mice $(30 \pm 5 \mathrm{~g})$ were used. Animals' ovaries were surgically removed and one cannula was inserted into their skull under deep anesthesia. One week later, animals were received $17-\beta$-estradiol either IP $(0.05,0.01,0.1 \mathrm{mg} / \mathrm{kg}) 30 \mathrm{~min}$ before or ICV $(0.05,0.01,0.1 \mu \mathrm{g} / \mathrm{mouse}) 5 \mathrm{~min}$ before the stress. Results showed that acute and chronic stress, increased plasma cortisol concentration in ovariectomized mice, but IP and ICV injection of 17- $\beta$-estradiol after stress induction reduced plasma cortisol concentration. Stress decreased delay to eating time, food and water intake and weight of ovariectomized animal significantly decreased. ICV and IP administration of estradiol in acute stress reduced delay to eating time significantly, but did not any change in water intake. In the acute stress IP administration of estradiol significantly, decreased food intake. In chronic stress both intraperitoneal and intraventricular administration of estradiol caused significant reduction in food intake in ovariectomized mice. Moreover, Stress reduces the brain to the adrenal volume ratio, which, IP and ICV administration of estradiol could inhibit this effect. It can be concluded that $17-\beta$-estradiol has different effects when administered IP or ICV on stress-induced metabolic changes in the ovariectomized mice.
\end{abstract}

\section{INTRODUCTION}

Stress is a response to anything that causes a disruption of the internal balance (homeostasis) and commonly relate to experiences that cause feelings of frustration and anxiety (McEwen, 2006; Rezaeian et al., 2016). Stress responses include changes in behavior, autonomic function, hormone secretion, metabolic and tissue changes and also changes in protein expression levels (McEwen \& Gianaros, 2011). If the stress is chronic and uncontrollable, it causes emotional disorders, anxiety and depression (Mah et al., 2016). Repeated and chronic stress can lead to hypothalamic-pituitary-adrenal (HPA) axis dysfunction (Asalgoo et al., 2015; Szabo et al., 2012). One of the

\footnotetext{
* Corresponding Author

Gholam Hossein Meftah, Neuroscience Research Center,

Baqiyatallah, University of Medical Sciences, Tehran, Iran.

Email:meftahi208@yahoo.com
}

the important effects of stress is changes in appetite and nutritional systems (Nishiyama et al., 2008). Metabolic disorders which are one of the most important consequences of social life in the last century are caused by stress (Erfani et al., 2016; Tamashiro et al., 2011). Also, a lot of diseases such as diabetes, cardiovascular diseases, chronic fatigue, depression, anxiety and autoimmune diseases are directly related to stressful life (McEwen, 2006; Hatef et al., 2015). There are gender differences in the incidence and onset of stress-related disorders and other mental disorders that these differences can be attributed to the effects of sex hormones ((McEwen, 2007; Verma et al., 2011; Herzog et al., 2009). Animal models for psychiatric disorders are mainly based on male animals, which the main reason for not using female animal is their estrous cycle and the variation of sex hormones per phase. Female sex hormones such as progesterone and estrogen affect in emotion and cognition behaviors which this leads to sex differences in behavior (ter Horst et al., 2012). 
On the other hand, women respond differently to stress than men, which might be related to the phases of the estrous cycle (ter Horst et al., 2012; Bowman et al., 2009; Chalabi-Yani et al., 2015). In animals, it has been shown that stress-induced corticosterone and adrenocorticotropin levels are higher in the female than in males (Kudielka and Kirschbaum, 2005). Memory and cognition functions are mediated by the hippocampus (Eslamizade et al., 2015; Meftahi et al., 2014; Meftahi et al., 2015). It is well accepted that chronic stress produces deficiency in hippocampal-dependent memory in male rats, but increases it in females (Bowman, 2005; Luine, 2007). Also, Galea et al. (1997) showed that apical dendritic atrophy in CA3 pyramidal neurons is seen in male, but not female brains in stress. If estrogen signaling in the brains of females was blocked, stress displayed destructive effects on them and when estrogen signaling was activated in males, the destructive effects of stress were inhibited. Also, aromatase enzyme (which is responsible for producing estrogen) levels, which producing estrogen is significantly higher in the prefrontal cortex of female rats that causes resilience against stress (Wei et al., 2014).

Thus the relationship between HPA and behavioral responses to stress are not the same in male and female animals and explain that there are sex differences in the pathways regulating the stress response. Despite the exact mechanisms are unknown, estradiol plays a crucial role in generating these sex differences effects of stress on central processes.

Although studies investigated the effects of estrogen during stress, but, there is a lack of studies on the effect of estrogen on metabolic changes during stress. Therefore, the aim of this study was to evaluate the protective effect of intraperitoneal and intraventricular injection of 17 beta-estradiol on plasma cortisol concentration and metabolic changes such as delay to eating (anorexia), water and food intake, weight change, an additional aim was to clarify changes in the ratio of brain volume to adrenal gland volume after acute and chronic stress in ovariectomized female NMRI mice.

\section{MATERIALS AND METHODS}

\section{Animals}

Female NMRI mice $(30 \pm 5 \mathrm{~g}, 6$ mice for each experiment) were used throughout the study.

The animals were housed in groups of six per cage under a $12 \mathrm{~h} / 12 \mathrm{~h}$ light/cycle and controlled temperature $24-22{ }^{\circ} \mathrm{C}$, with ad libitum food and water available. The animals were housed in the standard animal room for two weeks before starting the study to adaptation. Amount of food and water in each cage were calculated as water and food intake.

Vaginal Smear was taken from all the animals and their sexual cycle was examined before tests and all animals were in a proestrus phase. All Experiments were done in accordance with standard ethical guidelines and approved by the local ethical committee (The Baqiyatallah University of Medical Committee on the Use and Care, 81/021, July 10, 2014).

\section{Drugs}

The following drugs were used throughout the experiments: estradiol (Abu-Rayhan- Iran), ketamine hydrochloride and diazepam (Sigma, St. Louis, MO, USA). Estradiol was dissolved in oil and administered in intraventricular $(0.1,0.1,0.05 \mu \mathrm{g} /$ Mouse) five minutes and intraperitoneal (0.1, $0.1,0.05 \mathrm{mg} / \mathrm{kg}$ ) 30 minutes before the stress induction. Ketamine hydrochloride (Sigma, US) and diazepam hydrochloride (Sigma, US) were dissolved in sterile saline. The control group received oil.

\section{Experimental procedure}

Ovariectomy surgical procedure was performed according to the procedure described by Waynforth (Waynforth, 1980). Anesthetizing was performed by intraperitoneal injection of ketamine hydrochloride (50-75 $\mathrm{mg} / \mathrm{kg}$ ) and diazepam $(5-7 \mathrm{mg} /$ $\mathrm{kg}$ ). In order to ovariectomy, a small middle dorsal incision (2-1 $\mathrm{cm}$ ) was made to the 13th ribs, fallopian tubes along with blood vessels were closed and both ovaries were removed (bilateral ovariectomy). Finally, the incision was sutured. In order to sterilize the sides, betadine solution and penicillin powder were used. In the control group, surgical procedures were performed like ovariectomy group, but the ovaries were not removed. After surgery, the animals were housed individually in cages for a period of one week to allow recovery.

\section{Cannulation}

First, the animals were anesthetized by Ketamine hydrochloride (75-50 mg / kg) and diazepam (7-5 mg / kg). Then, a steel guide cannula was implanted in the animal's head by stereotaxic device according to Paxinos and Franklin atlas Coordinates (Paxinos and Franklin, 2001) for the lateral ventricles, $(\mathrm{AP}=+0.9 \mathrm{~mm}, \mathrm{ML}= \pm 2 \mathrm{~mm} \mathrm{DV}=3 \mathrm{~mm})$ and fixed in place using a lens screw and dental cement. Then, a thin wire with same size as the steel guide cannula was placed inside it to prevent the closure of guide cannula.

\section{Stress induction}

The animals were randomly allocated to experimental and control groups. In the experimental group animals were ovariectomized and were divided into two acute and chronic stress groups. Estradiol was injected intraperitoneal and intraventricular (one-side; left) to the experimental group. Estradiol injected intraperitoneal $(0.01,0.1,0.5 \mathrm{mg} / \mathrm{kg}) 30$ minutes before induction of chronic stress and injected intraventricular $(0.01,0.1,0.5 \mu \mathrm{g} /$ rat), five minutes before the induction of acute stress and then, to stress induction the animals were placed into a Communication Box. The device consists of nine separate sections $(50 \times 16 \times 16$ $\mathrm{cm}$ ) made of plexiglass with tiny holes that allow olfactory and auditory communication. Steel bars (with a $4 \mathrm{~mm}$ diameter) are placed on the floor of the instrument at $1.3 \mathrm{~cm}$ distance apart, through which electric shock is transmitted to the animal's soles.

The duration and intensity of the induced shock were controlled by a computer connected to the communication box (60 
$\mathrm{mV}, 10 \mathrm{~Hz}$, for $60 \mathrm{~s}$ ). The electric shock was induced randomly between the 9-13 hours. In order to adapt animals to the environment, they were transferred to the test room 60 minutes before the induction of the stress, and remained there 30 minutes before and 30 minutes after the induction of the stress. The control animals were placed in the device for 60 minutes without receiving any shock.

In chronic stress electric shock induction continued for seven consecutive days and in acute stress electric shock was induced one day. After the stress, the animals were returned to the cage.

After completing the tests, animals were anesthetized with high doses of ketamine, then their brain and adrenal glands were removed and kept in $4 \%$ formalin solution for fixation. Sixty days later, brain and adrenal glands were removed from formalin. The weight and volume of the brain and adrenal glands were measured by mercury immersion. Weight, food and water intake, delay to eating (the elapsed time between mices replacement in the home cage and beginning food intake was calculated as a delay to eating or anorexia) and plasma cortisol levels were measured as metabolic parameters in both stress and control groups.

\section{Measuring the concentration of cortisol hormone}

One day before the experiment and seven days following the induction of the stress, blood samples were taken from all the animals through their retro-orbital sinus $(0.5 \mathrm{ml}$ blood in $0.5 \mathrm{ml}$ of EDTA 3\%) and were centrifuged at $3000 \mathrm{rpm}$ for five minutes at $4{ }^{\circ} \mathrm{C}$. Then, the animals' supernatant plasma was collected for measuring cortisol levels using a cortisol measurement kit (Cortisol ELISA kit; 4164; DRG Instruments GmbH, Germany) at $450 \mathrm{~nm}$.

\section{Data analysis}

The data were expressed as mean \pm S.E.M. In order to analyze the data one-way and two-way analysis of variance (ANOVA), followed by Tukey test were used. $\mathrm{P}<005$ was considered significant differences.

\section{RESULTS}

\section{Effect of intraperitoneal and intraventricular injection of estradiol on plasma cortisol level after induction of acute and chronic stress}

The results were considered 100, in the first day, and for the other days it is evaluated according to first day (percentage). The results showed that acute and chronic stress significantly increased plasma cortisol compared to the control group (Figure 1A). IP administration of estradiol could inhibit the effects of acute stress and significant decrease of cortisol concentrations, compared to the stress group. Also, ICV administration of estradiol also caused a significant reduction in cortisol concentration compared to stress (Figure 1A). Moreover, the results showed that chronic stress was also an increase in plasma cortisol. On the other hand only the ICV administration of estradiol and only in doses of $0.1 \mu \mathrm{g} /$ mouse could lead to a significant reduction in plasma cortisol levels, compared to the stress group (Figure 1B).
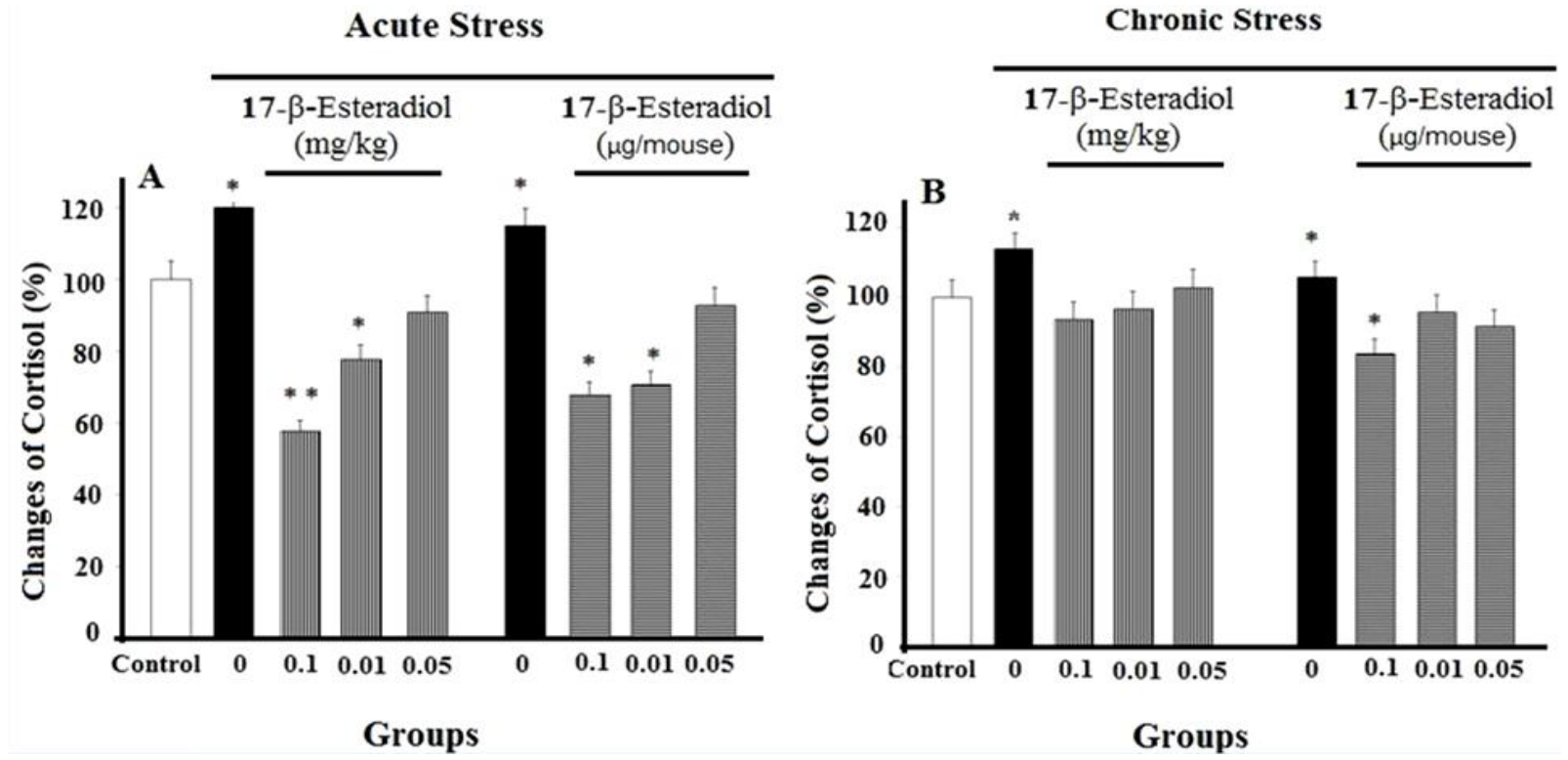

Fig. 1: Effect of intraperitoneal and intraventricular injection of estradiol on plasma cortisol during induction of acute (A) and chronic stress (B). Mean \pm S.E.M for 6 animals. $* \mathrm{P}<0.05$ and $* * \mathrm{P}<0.01$ is a significant difference compared to the control group. 
Effects of intraperitoneal and intraventricular injection of estradiol on delay to eating after induction of acute and chronic stress

The results showed that acute stress decreased delay to eating time in gonadectomized animal significantly, compared to controls. On the other hand, IP administration of estradiol at doses of 0.1 and $0.01 \mathrm{mg} / \mathrm{kg}$ in acute stress reduced delay to eating time significantly compared to acute stress groups. However, ICV injection of estradiol had different results than IP injection, which by reducing the estradiol dosage, the delay to eating time decreased (Fig. 2 A). Also, results showed that chronic stress reduces the delay to eating time in the ovariectomized animals, compared to the control group. IP administration of estradiol significantly increased delay to eating than chronic stress group and gradually reduce of the estradiol doses increased delay to eating, compared to the stress group. ICV injection of estradiol in 0.1 and $0.05 \mathrm{mg} / \mathrm{kg}$ reduced delay to eating compared to chronic stress group (Fig. $2 \mathrm{~B}$ ).

\section{Effects of intraperitoneal and intraventricular estradiol injection in water intake after induction of acute and chronic} stress

As shown in Figure 3 A, acute stress caused a significant reduction in water intake, compared to the control group. However, intraperitoneal and intraventricular injection of estradiol in ovariectomized mice did not cause any change in water intake, compared to stress group. Also, as shown in Figure $3 \mathrm{~B}$, chronic stress also causes a significant reduction in water intake in ovariectomized mice, compared to the control group. Intraventricular and intraperitoneal injections of estradiol in ovariectomized mice didn't change water intake, compared to the chronic stress group.
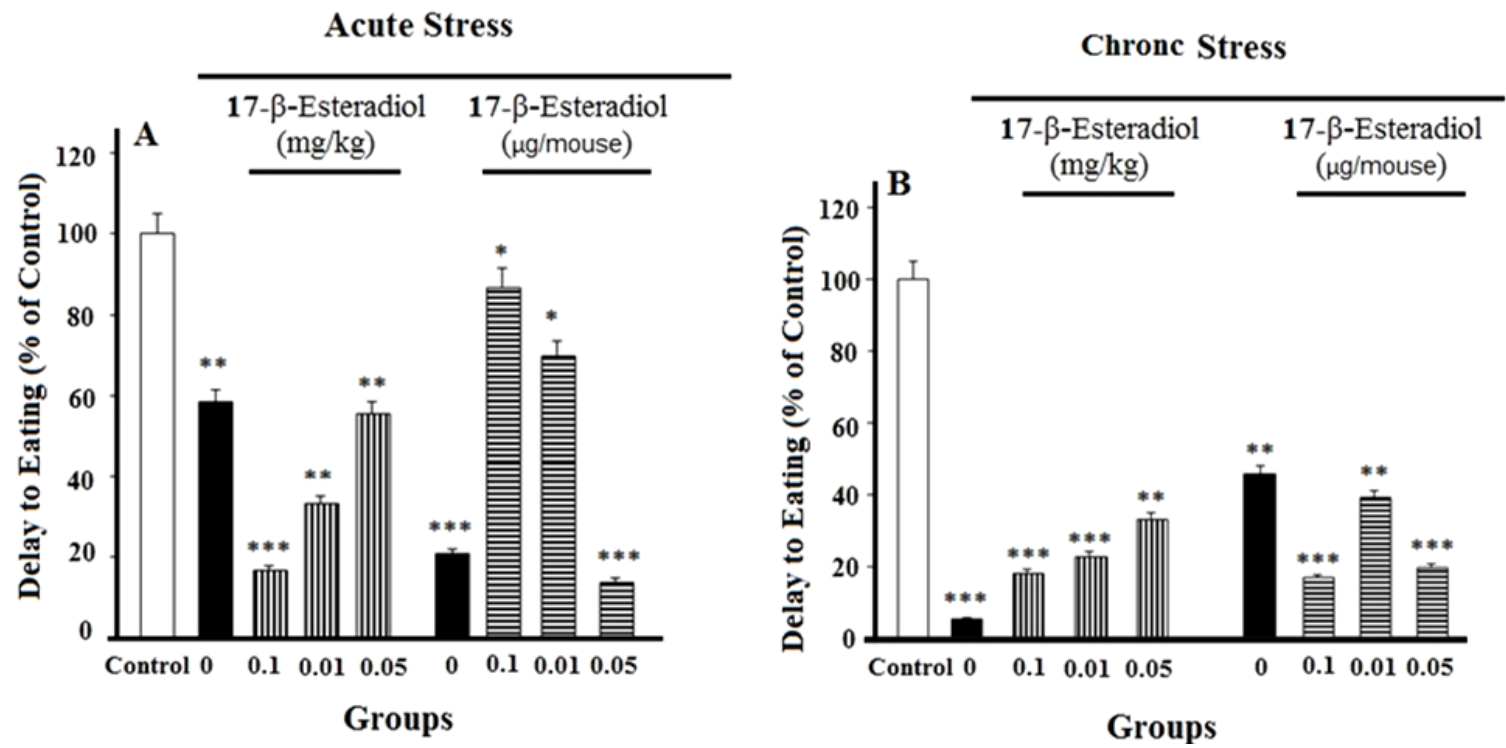

Fig. 2: Effect of intraperitoneal and intraventricular injection of estradiol on delay to eating during induction of acute (A) and chronic stresses (B). Mean \pm S.E.M. for 6 animals. $* \mathrm{P}<0.05, * * \mathrm{P}<0.01, * * * \mathrm{P}<0.001$ is a significant difference compared to the control group.
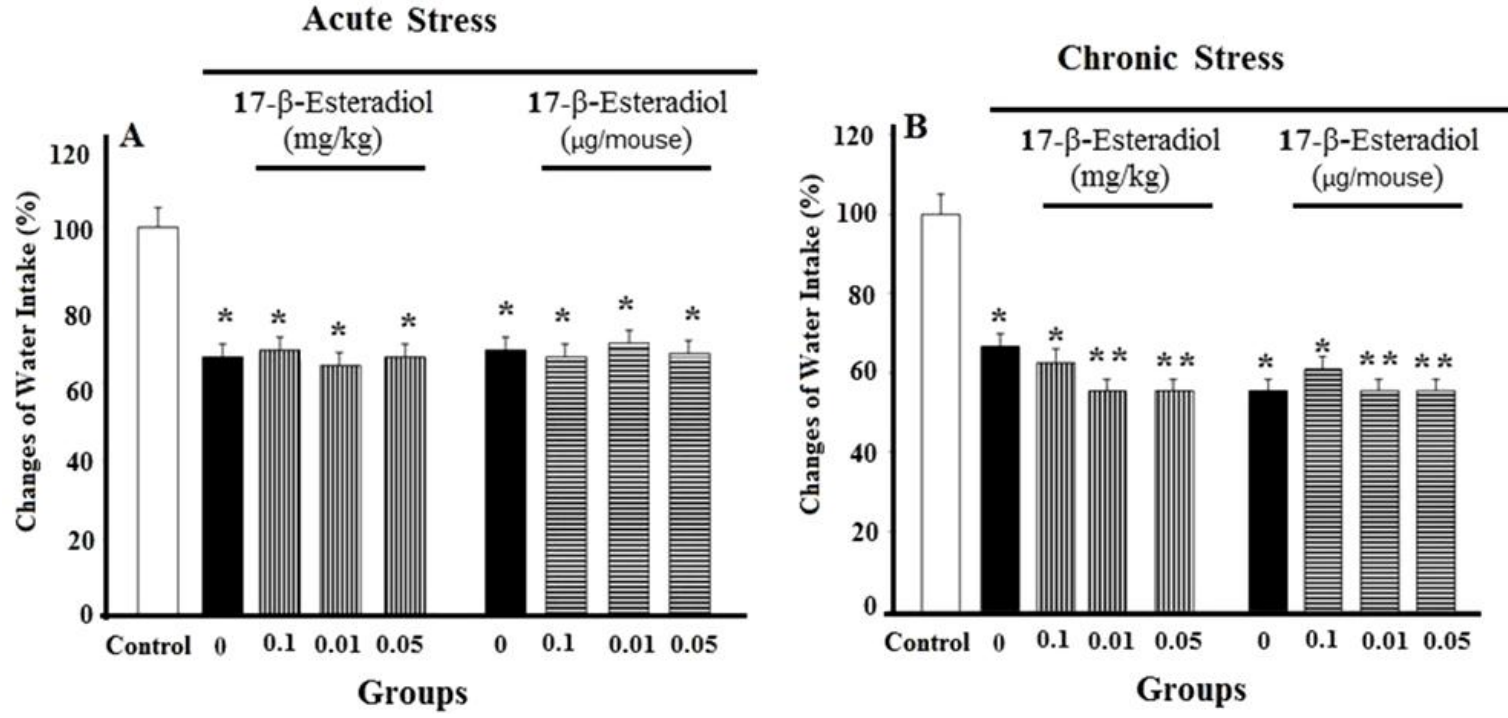

Fig. 3: Effect of intraperitoneal and intraventricular injection of estradiol in water intake during induction of acute (A) and chronic stress (B). Mean \pm S.E.M. for 6 animals. $* \mathrm{P}<0.05, * * \mathrm{P}<0.01$ is a significant difference compared to the control group. 

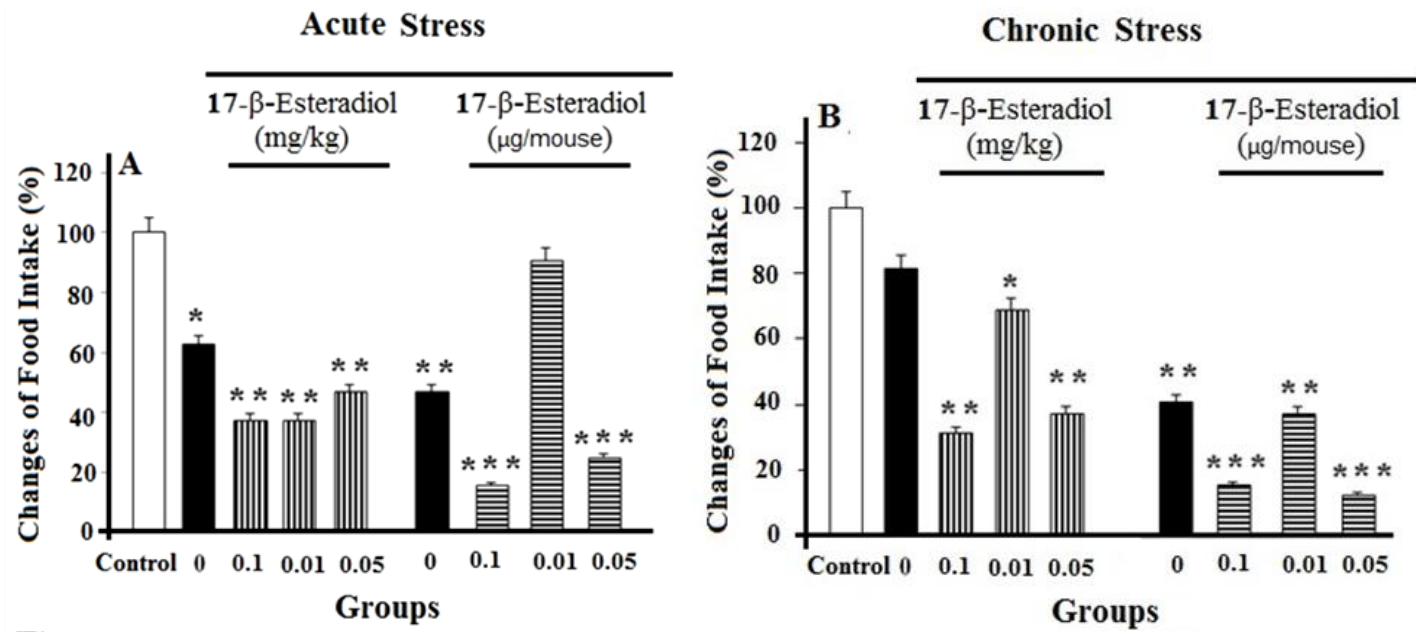

Fig. 4: Effect of intraperitoneal and intraventricular injection of estradiol on food intake during induction of acute (A) and chronic stress (B). Mean \pm S.E.M. for 6 animals. $* \mathrm{P}<0.05, * * \mathrm{P}<0.01, * * * \mathrm{P}<0.001$ is a significant difference compared to the control group.
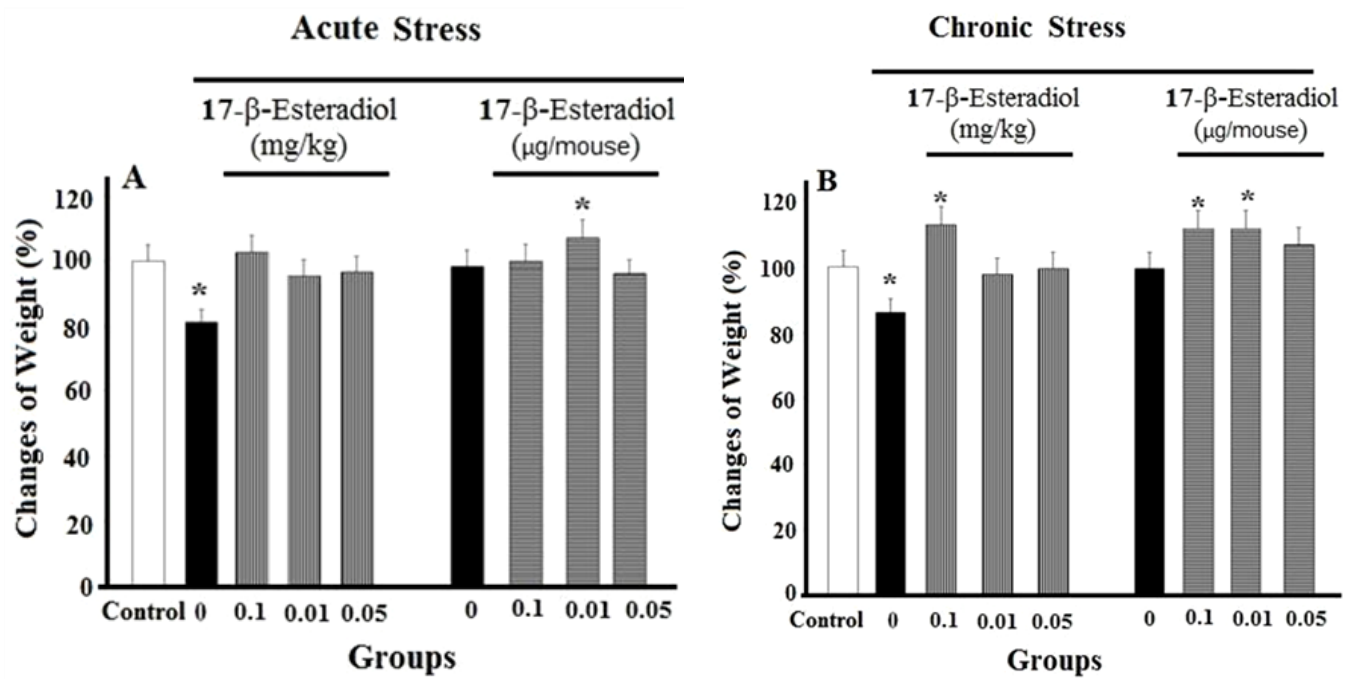

Fig. 5: Effect of intraperitoneal and intraventricular injection of estradiol on change of weight during induction of acute (A) and chronic stress (B). Mean \pm S.E.M. for 6 animals. $* \mathrm{P}<0.05$ is a significant difference compared to the control group.

\section{The Effect of intraventricular and intraperitoneal} administrations of estradiol on food intake after induction of acute and chronic stress

The results showed that acute stress caused a significant reduction in food intake in ovariectomized mice, compared to the control group. On the other hand, in the acute stress intraperitoneal administration of estradiol significantly decreased food intake compared to the stress. ICV injection of estradiol at a 0.01 $\mu \mathrm{g} /$ mouse significantly increased food intake compared to the stress group.

However, the ICV injection of estradiol at 0.1 and 0.05 $\mu \mathrm{g} /$ mouse caused a significant reduction in food intake in ovariectomized animals, compared to stress group (Figure $4 \mathrm{~A}$ ). The present results also showed that chronic stress led to a significant reduction in food intake in ovariectomized mice. Both IP and ICV administration of estradiol caused significant reduction in food intake in ovariectomized mice, compared to stress group (Figure 4 B).

\section{Effect of intraventricular and intraperitoneal injection of estradiol on weight changes after induction of acute and chronic stress}

Figure 5 A shows the effect of different doses of intraperitoneal and intraventricular estradiol on weight changes following acute stress. Acute stress causes weight loss in ovariectomized animals, compared to the control group. Both intraventricular and intraperitoneal administration of estradiol significantly increased the weight in ovariectomized animals, compared to the stress group ( $\mathrm{P}<0.05)$. As shown in Figure $5 \mathrm{~B}$ chronic stress also causes weight loss in ovariectomized animals, compared to the control group and intraventricular and intraperitoneal administration of estradiol significantly increased the weight in ovariectomized animals, compared to stress group ( $\mathrm{P}$ $<0.05)$. 

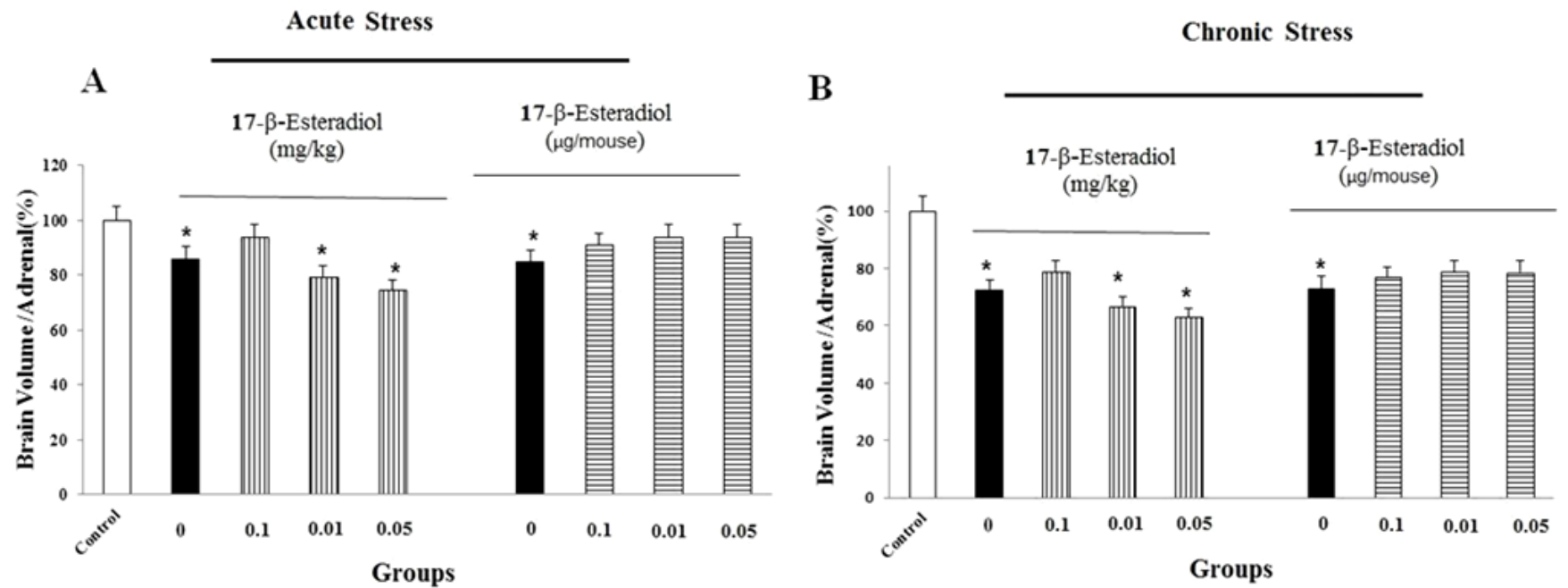

Fig. 6: Effects of acute (A) and chronic stress (B) of changes in the ratio of brain volume/adrenal gland. Animals received different doses of estradiol intraventricular $(0.1,0.1$ and $0.05 \mu \mathrm{g} /$ mouse $) 5$ minutes and intraperitoneal $(0.1,0.01,0.05 \mathrm{mg} / \mathrm{kg}) 30$ minutes before stress induction. Mean \pm S.E.M. for 6 animals. *P $<0.05$ compared to the control group.

\section{The effect of intraperitoneal and intraventricular administration of estradiol on brain volume/adrenal gland volume after induction of acute and chronic stress}

The results showed that acute stress can decrease the ratio of brain to adrenal gland volume in animals. Intraperitoneal administration of estradiol only at a dose of $0.1 \mathrm{mg} / \mathrm{kg}$ could inhibit this effect. Intraventricular administration of estradiol in all three doses $(0.1,0.01$ and $0.05 \mu \mathrm{g} /$ mouse) inhibited stress effect in ovariectomized mice (Figure 6 A). [Two-Way ANOVA; estradiol effect: $\mathrm{F}(1,60)=2.11, \mathrm{P}<0.05$, side effect: $\mathrm{F}(2,60)=1.24$, $\mathrm{P}<0.05$, side $\times$ estradiol effects: $\mathrm{F}(10,60)=3.22, \mathrm{P}<0.05]$. The results showed that chronic stress also decreased brain/adrenal gland volume in stressed animals. Intraperitoneal injection of estradiol only at a dose of $0.1 \mathrm{mg} / \mathrm{kg}$ could inhibit this effect. However, intraventricular injection of estradiol in all three doses of estradiol was able to increase the ratio of brain/adrenal gland volume in chronic stress animals (Figure b -6). [Two-Way ANOVA; estradiol effect: $\mathrm{F}(1,60)=1.98, \mathrm{P}<0.05$, side effect: $\mathrm{F}$ $(2,60)=1.343, \mathrm{P}<0.05$, side $\times$ estradiol effects: $\mathrm{F}(10,60)=$ 1.87, $\mathrm{P}<0.05$; left side].

\section{DISCUSSION}

In the present study, the effects of both intraperitoneal and intraventricular administration of estradiol after acute and chronic uncontrolled stress (or inevitable), on plasma cortisol, anorexia, water and food intake, body weight and brain/adrenal volume in ovariectomized female mice were studied. The results showed that acute and chronic stress, increased plasma cortisol concentration which, injection of estradiol in ovariectomized mice could inhibit the effects of stress and a slight decrease plasma cortisol levels. Stress, particularly emotional stress has plenty of biomarkers but, increased plasma levels of glucocorticoid hormones such as cortisol and corticosterone are known as a potential marker for the diagnosis of stress. Studies have shown that stress can increase HPA axis activity and therefore increase glucocorticoid hormones such as corticosterone and cortisol as one of the most important indicators of stress (Cohen et al., 2012). However, Studies showed that corticosterone is the main glucocorticoid in rodents and especially mice, but also cortisol increase in mice during the stress (Gong et al., 2015) and in this study, we measured plasma cortisol concentration which stress caused significant increased in plasma cortisol concentration.

Estradiol is steroid and can cross the blood-brain barrier. Also, estrogen is produced locally in the brain. The estrogen produced in the brain may play an important role in keeping the brain's autonomic tone (McEwen et al., 2012). Estrogen could change neurotransmitter system function in the brain, like GABAergic, glutamatergic, dopaminergic and serotonergic system and alter the behavioral and electrophysiological function of brain (Barth et al., 2015). Estrogen receptors exist in many brain regions and estrogen's signaling could prevent the harmful effects of stress (Toran-Allerand, 2005). Estrogen receptors via activation of the MAPK pathways, participates in mediating neuroprotection (Fiocchetti et al., 2012). Estrogen via multiple mechanisms, such as increasing the inhibitory effects of glucocorticoids on the HPA axis, reducing corticosterone and cortisol metabolism, increases the synthesis of corticosterone or cortisol and increased sensitivity or reduces the degradation of glucocorticoid receptors, affects the stress response (Bagheri Nikoo et al., 2014). In the present study, perhaps decreasing effect of estradiol administration on plasma cortisol concentrations after acute and chronic stress is through these mechanisms.

In another part of this study the results showed that acute and chronic stress in ovariectomized mice decreased weight, food and water intake. In acute and chronic stress intraperitoneal and intraventricular administration of estradiol at 0.1 and 0.01 doses cause weight gain in animals. 
The results also showed that intraperitoneal administration of estradiol decreases anorexia in acute stress (especially in $0.1 \mathrm{mg} / \mathrm{kg}$ ), but in $0.05 \mathrm{mg} / \mathrm{kg}$ anorexia increased. In acute stress intraventricular injection of estradiol at a dose 0.05 $\mu \mathrm{g} /$ mouse decreased anorexia significantly, but in 0.1 and $0.01 \mu \mathrm{g} / \mathrm{mouse}$ anorexia increased than the acute stress group. It is believed that overeating due to stress, may lead to metabolic diseases such as obesity and diabetes (Mikolajczyk et al., 2009). High concentrations of cortisol in plasma and brain cause brain reward system to get highly sensitive and this sensitivity increased tendency to use fat and feeding activity. Cortisol may affect the reward value of food via peptide mediators such as ghrelin (Yau and Potenza, 2013).

Ghrelin is a peptide which increases appetite that is produced mainly in the stomach and is seen in the blood circulation of healthy human, but its concentration increased in people under stress. It has been shown that ghrelin also play a similar role to increases of food intake, weight gain and obesity in rodents as in humans (Patterson et al., 2011). Since chronic stress can lead to exposure of the brain and body to high levels of cortisol and this have direct and indirect effects on reward systems. In the acute stress the HPA axis modulation of food intake allows the stressful phenomenon to be reduced with and the energy used to be replaced afterward, but, in chronic stress glucocorticoids can lead to chronically stimulate eating behavior and excessive weight gain. In addition, stress can increase palatable food via its interaction with central reward pathways. Activation of this system can also interface with the HPA axis to inhibit its more activation, which means not only can stress, enhance eating behavior, but eating can inhibit the HPA axis and stress (Yau and Potenza, 2013; Sominsky and pencer, 2014).

The results of this study showed that acute and chronic stress reduced water intake in female mice. However, it has been shown that stress could increase water intake by stimulating the secretion of CRF and vasopressin, which inconsist with our results (Elman et al., 2003). However, previous studies showed that the effects of stress in male mice are different from female. For instance, Ranjbaran et al. (2013) and Bagheri Nikoo et al. (2014) have been shown that electro foot shock stress in male mice increased water intake. Estrogen receptors contain two major types (ER $\alpha$ and $E R \beta$ ) which, describing ER $\beta$ express at high levels by neurons within the paraventricular nucleus (PVN) and a large percent of ER $\beta$ cells in the PVN are arginine vasopressin (AVP) positive, but ER $\beta$ is also found in some $\mathrm{CRH}$ containing neurons of the PVN. ER $\alpha$ is found at low levels and just in the periventricular PVN and barely in $\mathrm{CRH}, \mathrm{AVP}$ or oxytocin neurons, which prevent a direct action of estradiol as mediated through ER $\alpha$ on PVN responses to stress. Nonetheless, ER $\alpha$ is colocalised with GAD67 (the enzyme which involve in the synthesis of GABA) in neurons surrounding the PVN. One explanation from this localization would be that ER $\alpha$ can modulate inhibitory input to the PVN, hence affecting HPA axis function through trans-synaptic mechanisms (Handa et al., 2009; Miller et al., 2004; Bahari et al., 2015). This may be able to explain, which water intake decreased during stress in female mice. In other part of this study, the effect of acute and chronic stress on the changes in the ratio of brain volume/adrenal gland volume was measured. Results showed that stress can cause a decrease in the ratio of brain volume to adrenal gland volume. In the present study, estradiol inhibited the damaging effects of stress, so that intraperitoneal injection of estrogen $(0.1 \mathrm{mg} / \mathrm{kg})$ and ICV injection (0.1, 0.01 and $0.05 \mu \mathrm{g} / \mathrm{mouse})$ increased brain volume/ adrenal gland volume.

The brain is a target of stress, which showing stressinduced dendrite atrophy and shrinkage, loss of dendrite spines in neuronal populations, heightened susceptibility to cell death and decreased size and weight of some parts of the brain such as the hippocampus (Lee et al., 2009; Liston et al., 2006). Thus, it seems that stress could damage the neurons, but estradiol by binding to its receptor activates neurite growth, such as nerve growth factor (NGF) and brain-derived nerve growth factor (BDNF), increase synaptogenesis, modulating immediate-early-gene expression, kinase activity and calcium handling and prevents neuronal damages (McCarthy, 2008 ). Also, there is indicating that in older women, due to lower estrogen levels during menopause, brain volume began to decrease. This atrophy occurs particularly in the hippocampus and the parietal lobe that these areas associated with memory and cognition. Thus, lack of estrogen affected this area of the brain and can cause atrophy and impairment in learning and memory (Shepherd, 2001). Glutaminergic system is another mechanism that can be changed during stress. Acute exposure to stress rapidly increases glutamate release in several limbic and cortical areas, including the preferontal cortex, hippocampus and amygdala (Bahari et al., 2014; Husseini et al., 2016; Venero and Borrell, 1999). It has been shown that repeated unpredictable stress causes a loss of surface AMPAR and NMDAR glutamate subunits in preferontal neurons and the level of total NR1 and GluR1 subunits in the preferontal is also greatly reduced by repeated exposure to stress (Yuen et al., 2012).

Thus, in chronic stress animals' disrupted membrane trafficking or synthesis of glutamate receptors may contribute to the loss of glutamatergic transmission and could damage neurons. Yokomaku et al. showed that estrogen exhibit facilitating effect on glutamate transmission (Yokomaku et al., 2003). The mechanisms which estrogen effects on cognition are related to NMDA glutamate receptors. For instance, it has been shown that estrogen promotes an increase in NMDA receptor subunit expression and binding sites and improves neuronal function and prevents neuronal damage (Adams et al., 2004).

Ulrich-Lai et al. displayed that chronic stress, increase weight of the adrenal gland by hyperplasia of the outer zona fasciculate and hypertrophy of the inner zona fasciculata and medulla. Thus, these findings are consistent with the present results demonstrating brain volume/adrenal volume decrease during stress. Stress also increased adrenal medullary size and/or catecholamine content is frequently observed after other types of stress. Furthermore, after stress there is a generalized raise in medullary function, which suggesting that medullary hypertrophy 
may be a general consequence of chronic stress (Hosseini et al., 2015; Miyamoto et al., 1999; Rezaeian Dalooei et al., 2016; Ghodrat et al., 2014).

\section{CONCLUSION}

Therefore, these findings suggest that administration of intraperitoneal (IP) and intraventricular (ICV) injection of estradiol in female adult ovariectomized mice can protect against the hormonal and metabolic changes of acute and chronic stress. Among the indications of these results are those understandings the mechanisms of estrogen neuroprotection will allow for the development of more effective estrogenic agents useful for the treatment of stress.

\section{ACKNOWLEDGEMENTS}

Financial support and sponsorship: This work is a part of the thesis of Ghobadi, which was funded by the Neuroscience Research Center of Baqiyatallah University of Medical Sciences, Tehran, Iran.

Conflict of Interests: There are no conflicts of interest.

\section{REFERENCES}

Adams MM, Fink SE, Janssen WG, Shah RA, Morrison JH. Estrogen modulates synaptic N-methyl-D-aspartate receptor subunit distribution in the aged hippocampus. J Comp Neurol, 2004; 474: 419426.

Asalgoo G, Jahromi GP, Meftahi GH, and Sahraei H. Posttraumatic Stress Disorder (PTSD): Mechanisms and Possible Treatments. Neurophysiol, 2015; 47:482-489.

Bagheri Nikoo G, Khosravi M, Sahraei H, Ranjbaran M, Sarahian S, Zardooz H, Bourbour Z, Alemaref M, Pirzad Jhromi G, Herfehdoost G. Effects of systemic and intra-accumbal memantine administration on the impacts of plantar electrical shock in male NMRI mice. Physiol Pharmacol, 2014; 10: 61-71.

Bahari Z, Manaheji H, Dargahi L, Daniali S, Norozian M, Meftahi GH, Sadeghi M. Time Profile of nNOS Expression in the Spinal Dorsal Horn after L5 Spinal Root Transection in Rats. Neurophysiology. 2015; 47(4): 287-94.

Bahari Z, Manaheji H, Hosseinmardi N, Meftahi GH, Sadeghi M, Danialy S, Noorbakhsh MS. Induction of spinal long-term synaptic potentiation is sensitive to inhibition of neuronal NOS in 15 spinal nervetransected rats. EXCLI, 2014; 13: 751-60.

Barth C, Villringerand A, Sacher J. Sex hormones affect neurotransmitters and shape the adult female brain during hormone al transition periods. Front Neurosci, 2015; 9: 1-20.

Bowman RE. Stress-induced changes in spatial memory are sexually differentiated and vary across the lifespan. J. Neuroendocrinol, 2005; 17: 526-535.

Bowman RE, Micik R, Gautreaux C, Fernandez L, Luine VN. Sex-dependent changes in anxiety, memory, and monoamines following 1 week of stress. Physiol Behav, 2009; 97: 21-29.

Chalabi-Yani D, Sahraei H, Meftahi GH, Hosseini SB, SadeghiGharajehdaghi S, Ali Beig H, Bourbour Z, Ranjabaran M. Effect of Transient Inactivation of Ventral Tegmental Area on the Expression and Acquisition of Nicotine-Induced Conditioned Place Preference in Rats. Iran Biomed J. 2015; 19 (4): 214-219.

Cohen S, Janicki-Deverts D, Doyle WJ, Miller GE, Frank E, Rabin BS, R. B. Turner RB. Chronic stress, glucocorticoid receptor resistance, inflammation, and disease risk. PNAS, 2012; 109: 5995-5999.
Elman I, Lukas S, Shoaf SE, Rott D, Adler C, Breier A. Effects of acute metabolic stress on the peripheral vasopressinergic system in schizophrenia. J Psychopharmacol, 2003; 17: 317-23.

Erfani M, Sahraei H, Bahari Z, Meftahi GH, Hatef B, Mohammadi A, Hosseini SH. Evaluation of the effect of time change in cognitive function in volunteers in tehran. Glob J Health Sci, 2016; 9(2): 119.

Eslamizade MJ, Saffarzadeh F, Mousavi SM, Meftahi GH, Hosseinmardi N, Mehdizadeh M, Janahmadi M. Alterations in CA1 pyramidal neuronal intrinsic excitability mediated by $\mathrm{Ih}$ channel currents in a rat model of amyloid beta pathology. Neurosci, 2015; 305 : 279-92.

Fiocchetti M, Ascenzi P, Marino M. Neuroprotective Effects of $17 \beta$-Estradiol Rely on Estrogen Receptor Membrane Initiated Signals. Front Physiol, 2012; 3:73.

Galea LA, McEwen BS, Tanapat P, Deak T, Spencer RL, Dhabhar FS. Sex differences in dendritic atrophy of CA3 pyramidal neurons in response to chronic restraint stress. Neurosci, 1997; 8: 689697.

Ghodrat M, Sahraei H, Razjouyan J, Meftahi GH. Effects of a Saffron Alcoholic Extract on Visual Short-Term Memory in Humans: a Psychophysical Study. Neurophysiology. 2014; 46 (3): $247-$ 253.

Gong S, Miao YL, Jiao GZ, Sun MJ, Li H, Lin J, Luo MJ, Tan $\mathrm{JH}$. Dynamics and correlation of serum cortisol and corticosterone under different physiological or stressful conditions in mice. PLoS one, 2015; 20: e0117503.

Handa RJ., Weiser MJ, Zuloaga DG. A Role for the Androgen Metabolite, $5 \alpha$-Androstane-3 $\beta, 17 \beta$-Diol, in Modulating estrogen Receptor $\beta$-Mediated Regulation of Hormonal Stress Reactivity. J Neuroendocrinol, 2009; 21: 351-358.

Hatef B, Ghanjal A, Meftahi GH, Askary-Ashtiani A. Isokinetic and Electromyographic Properties of Muscular Endurance in Short and Long-Term Type 2 Diabetes. Glob J Health Sci, 2015; 8(8): 210.

Herzog CJ, Czéh B, Corbach S, Wuttke W, SchulteHerbrüggen O, Hellweg R, Flügge G, Fuchs E. Chronic social instability stress in female rats: a potential animal model for female depression. Neurosci, 2009; 159: 982-92.

Hosseini SB, Sahraei H, Mohammadi A, Hatef B, Meftahi GH, Chalabi-Yani D, Alibeig H, Sadeghi-Gharajehdaghi S, and Ranjabaran. Inactivation of the Nucl. Accumbens Core Exerts No Effect on NicotineInduced Conditioned Place Preference. Neurophysiology, 2015; 47(4): 295-301

Husseini Y, Sahraei H, Meftahi GH, M. Dargahian M, Mohammadi A, Hatef B, Zardooz H, Ranjbaran M, Hosseini SB, Alibeig H, Behzadnia M. 2016. Analgesic and anti-inflammatory activities of hydro-alcoholic extract of Lavandula officinalis in mice: possible involvement of the cyclooxygenase type 1 and 2 enzymes. Revista Brasileira de Farmacognosia. 26 (1): 102-108.

Kudielka BM, and Kirschbaum C. Sex differences in HPA axis responses to stress: a review. Biol Psychol, 2005; 69: 113-132.

Lee T, Jarome T, Li SJ, Kim JJ, Helmstetter FJ. Chronic stress selectively reduces hippocampal volume in rats: a longitudinal MRI study. Neuroreport, 2009; 25: 1554-1558.

Liston C, Miller MM, Goldwater DS, Radley JJ, Rocher AB, Hof PR, Morrison JH, McEwen BS. Stress-induced alterations in prefrontal cortical dendritic morphology predict selective impairments in perceptual attentional set-shifting. J Neurosci, 2006; 26: 7870-4.

Luine VN. The prefrontal cortex, gonadal hormones and memory. Horm Behav, 2007; 5: 181-182.

Luine VN, Beck KD, Bowman RE, Frankfurt M, MacLusky NJ. Chronic stress and neural function: accounting for sex and age. J Neuroendocrinol, 2007; 19: 743-751.

Mah L, Szabuniewicz C, Fiocco AJ. Can anxiety damage the brain? Current opinion in psychiatry, $1 ; 29(1)$ : 56-63

McCarthy MM. Estradiol and the Developing Brain. Physiol Rev, 2008; 88, 91-124.

Shepherd JE. Effects of estrogen on congnition mood, and degenerative brain diseases. J Am Pharm Assoc (Wash), 2001; 4: 221-8. 
McEwen BS. Protective and damaging effects of stress mediators: central role of the brain. Dialog Clinic Neurosci, 2006; 8: 367 381 .

McEwen BS, Akama KT, Spencer-Segal JL, Milner TA, Waters EM. Estrogen effects on the brain: actions beyond the hypothalamus via novel mechanisms. Behav neurosci, 2012 126(1):4.

McEwen BS, and Milner TA. Hippocampal formation: shedding light on theinfluence of sex and stress on the brain. Brain Res Rev, 2007; 55: $343-355$

McEwen BS, Gianaros PJ. Central role of the brain in stress and adaptation: Links to socioeconomic status, health, and disease. Ann New York Acad Sci, 2010;1186:190-222.

Meftahi G, Ghotbedin Z, Eslamizade MJ, Hosseinmardi N, Janahmadi M. Suppressive effects of resveratrol treatment on the intrinsic evoked excitability of CA1 pyramidal neurons. Cell Journal (Yakhteh), 2015; 17, 532-39.

Meftahi GH, Janahmadi M, Eslamizade MJ. Effects of resveratrol on intrinsic neuronal properties of CA1 pyramidal neurons in rat hippocampal slices. Physiology and Pharmacology. Physiol Pharmacol, 2014; 18: 144-155.

Mikolajczyk RT, El Ansari W, Maxwell AE. Food consumption frequency and perceived stress and depressive symptoms among students in three European countries. Nutr J Jul, 2009; 15: 8-31.

Miller W J, Suzuki S, Miller LK, Handa R, Uht RM. Estrogen receptor (ER) beta isoforms rather than ERalpha regulate corticotropinreleasing hormone promoter activity through an alternate pathway. J Neurosci, 2004; 24:10628-10635.

Miyamoto H, Mitani F, Mukai K, Suematsu M, Ishimura Y. Studies on cytogenesis in adult rat adrenal cortex: circadian and zonal variations and their modulation by adrenocorticotropic hormone. J Biochem (Tokyo), 1999; 126: 1175-1183.

Nishiyama M, Makino S, Iwasaki Y, Tanaka Y, Nazarloo HP, Kaneda T, Asaba K, Hashimoto K. CRH mRNA expression in the hypothalamic paraventricular nucleus is inhibited despite the activation of the hypothalamo-pituitary-adrenal axis during starvation. Brain Res, 2008; 4: 107-12.

Patterson M, Bloom SR, Gardiner JV. Ghrelin and appetite control in humans-Potential application in the treatment of obesity. Peptides, 2011; 32: 2290-2294.

Paxinos G, and Franklin KBJ. The mouse brain in stereotaxic coordinates. 2nd Edition, San Diego Academic Press, 2001.

Ranjbaran M, Mirzaei P, Lotfi F, Behzadi S, Sahraei H. Reduction of metabolic signs of acute stress in male mice by papaver Rhoaes hydro-alcoholic extract. Pakistan Jour of Biolog Sci, 2013; $16: 1016$.

Rezaeian Dalooei J, Sahraei H, Meftahi GH, Khosravi M, Bahari Z, Hatef B, Mohammadi A, Nicaeili F, Eftekhari F, Ghamari F, Hadipour M, Kaka G. Temporary amygdala inhibition reduces stress effects in female mice. J Adv Rese, 2016; 7: 643-649.

Singer CA, Figueroa-Masot XA, Batchelor RH, Dorsa DM. The mitogen-activated protein kinase pathway mediates estrogen neuroprotection after glutamate toxicity in primary cortical neurons. J Neurosci, 1999; 19: 2455-63.
Sominsky L, Pencer SSJ. Eating behavior and stress: a pathway to obesity. Front Psychol, 2014; 13: 1-8.

Szabo S, Tache Y, Somogyi A. The legacy of Hans Selye and the origins of stress research: A retrospective 75 years after his landmark brief. Stress, 2012; 15: 472-478.

Tamashiro KL., Sakai RR, Shively CA, Karatsoreos IN, Reagan LP. Chronic stress, metabolism, and metabolic syndrome. Stress, 2011; 14: 468-74.

ter Horst JP, de Kloet ER, Schächinger H, Oitzl MS. Relevance of Stress and Female Sex Hormones for Emotion and Cognition. Cell Mol Neurobiol, 2012; 32: 725-735.

Toran-Allerand CD. Estrogen and the brain: beyond ER-alpha, ER-beta, and 17beta-estradiol. Ann N Y Acad Sci, 2005; 1052: 136-44.

Ulrich-Lai YM, Figueiredo HF, Ostrander MM, Choi DC, Engeland WC, Herman JP. Chronic stress induces adrenal hyperplasia and hypertrophy in a subregion-specific manner. Am J Physiol Endocrinol Metab, 2006; 291: 965-73.

Venero C, and Borrell J. Rapid glucocorticoid effects on excitatory amino acid levels in the hippocampus: a microdialysis study in freely moving rats. Eur J Neurosci, 1999; 11: 2465-2473.

Verma R, Singh Balhara YP, Gupta CS. Gender differences in stress response: Role of developmental and biological determinants. Ind Psychiatry J, 2011; 20: 4-10.

Waynforth HB. Experimental and surgical techniques in the rat. London: Academic Press London, 1980.

Wei JE, Yuen Y, Liu W, Li X, Zhong P, Karatsoreos IN, McEwen BS, Yan Z. Estrogen protects against the detrimental effects of repeated stress on glutamatergic transmission nd cognition. Mol Psychiatry, 2014;19: 588-98.

Yau YH, and Potenza MN, 2013. Stress and eating behaviors. Minerva Endocrinol, 2013; 38: 255-67.

Yokomaku D, Numakawa T, Numakawa Y, Suzuki S, Matsumoto T, Adachi N, Nishio C, Taguchi T, Hatanaka H. Estrogen enhances depolarization-induced glutamate release through activation of phosphatidylinositol 3-kinase and mitogen-activated protein kinase in cultured hippocampal neurons. Mol Endocrinol, 2003; 17: 831-44.

Yuen EY, Wei J, Liu W, Zhong P, Li X, Yan Z. Repeated stress suppresses glutamate receptor expression and function in prefrontal cortex and impairs object recognition memory. Neuron, 2012; 73: 962-977.

\section{How to cite this article:}

Ghobadi N, Sahraei H, Meftah GH, Bananej M, Salehi S. Effect of estradiol replacement in ovariectomizedNMRI mice in response to acute and chronic stress. J App Pharm Sci, 2016; 6 (11): 176-184. 